NASA/TM-1999-209285

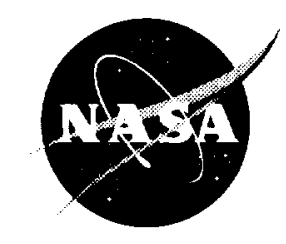

\title{
Fire Safety in the Low-Gravity Spacecraft Environment
}

Robert Friedman

Glenn Research Center, Cleveland, Ohio

Prepared for the

29th International Conference on Environmental Systems cosponsored by SAE Aerospace, ASME, AIAA, Aerospace Medical Association, and AIChE Denver, Colorado, July 12-15, 1999

National Aeronautics and Space Administration

Glenn Research Center 
This report is a preprint of a paper intended for presentation at a conference. Because of changes that may be made before formal publication, this preprint is made available with the understanding that it will not be cited or reproduced without the permission of the author.

Available from

NASA Center for Aerospace Information

7121 Standard Drive

Hanover, MD 21076

Price Code: A03
National Technical Information Service 5285 Port Royal Road Springfield, VA 22100

Price Code: A03 


\title{
Fire Safety in the Low-Gravity Spacecraft Environment
}

\author{
Robert Friedman \\ National Aeronautics and Space Administration \\ Glenn Research Center \\ Cleveland, Ohio 44135
}

\begin{abstract}
Research in microgravity (low-gravity) combustion promises innovations and improvements in fire prevention and response for human-crew spacecraft. Findings indicate that material flammability and fire spread in microgravity are significantly affected by atmospheric flow rate, oxygen concentration, and diluent composition. This information can lead to modifications and correla. tions to standard material-assessment tests for prediction of fire resistance in space. Research on smoke-particle changes in microgravity promises future improvements and increased sensitivity of smoke detectors in spacecraft. Research on fire suppression by extinguishing agents and venting can yield new information on effective control of the rare, but serious fire events in spacecraft.
\end{abstract}

\section{INTRODUCTION}

Fire is a particularly feared hazard in confined enclosures, as in spacecraft. A serious fire in an orbiting spacecraft is an event of very low probability; nevertheless, some fire threats are foreseeable. Obvious examples include those of electrical and heating overloads, spills and resulting aerosols, energetic experiment failures, and ignition of accumulated trash [1]. The overall spacecraft fire-safety strategy considers both the prevention of, and the response to, fires. Fire prevention, of course, implies that one or more of the three general firecausing factors, namely, ignition energy, fuel, or oxygen, can be eliminated. Fire response (since fire prevention is never guaranteed) implies that provisions are in place for early warning of breakdown events, intervention to limit and suppress the resulting fire, and restoration of normal conditions following the event [2].

This paper reviews the current state of the art in spacecraft fire safety and discusses the findings of microgravity combustion research as they relate to practical fire prevention and response.

\section{FIRE PREVENTION IN SPACECRAFT}

\section{FIRE PREVENTION BY ELIMINATION OF IGNITION SOURCES}

Spacecraft designs and operations must meet standards that serve to eliminate, or at least diminish, ignitionenergy threats. These requirements cover the usual practices of electrical bonding and grounding, electrical and thermal overload protection, working-pressure relief settings, and similar safety procedures. Spacecraft wireand cable-capacity allowances are highly conservative to limit stress and heating during normal operations. For example, maximum current values are derated to onehalf of the usual current allowance for $200{ }^{\circ} \mathrm{C}$ insulation service [3].

\section{FIRE PREVENTION BY MATERIAL SELECTION}

The major consideration in spacecraft fire prevention is that of the elimination of potential fuels. As far as possible, spacecraft materials and assemblies meet specified performance criteria of non-flammability, as determined by prior testing (on the ground). Spacecraft fire-prevention tests and standards are, for the most part, extensions of aircraft practices, but their philosophy of risk reduction differs from that of aircraft because of the particular needs of spacecraft safety. For example, structural and decorative panel materials for aircraft must meet standards of minimum heat-release rate upon ignition. This criterion is necessary to prevent or delay the growth of an established fire into flashover (generalized fire spread away from the point of origin), ensuring adequate escape time following crash fires. Similar panel materials for spacecraft, in contrast, must meet standards of a minimum flame-spread distance (self-extinguishment) upon ignition. This criterion is necessary to prevent ignition events from developing into fires of any significant size. 
Table 1. Test Methods for Evaluating the Flammability of Materials for Use in NASA Human-Crew Space Missions

Test

No.

Application

1 Sheets, coatings, foams, insulated wires

2 Sheets, coatings, foams that fail to meet the criteria of Test 1 ; also major-use nonmetals with greater than $0.37-\mathrm{m}^{2}$ exposure

3 Liquids, coatings

4 Insulated wires

8 Containers

17 Metals, nonmetals for oxygen service

For U.S. spacecraft, fire-resistant items are selected through testing standards defined in the NASA Handbook NHB 8060.1C [4]. Table 1 summarizes the principal flammability tests.

The test of widest application is Test 1 , which has been in use for over 25 years with minor upgrading. The performance criterion of Test 1 is the self-extinguishment of a $30-\mathrm{cm}$-long by $5-\mathrm{cm}$-wide sample, mounted vertically and ignited chemically at the bottom, before any resulting flame progresses for a distance of $15 \mathrm{~cm}$ or beyond (shown as the limiting flame-spread height on Fig. 1). Almost all materials spark or drip flaming particles when ignited. Therefore, in addition to the self-extinguishment criterion, an acceptable material must not ignite a sheet of paper mounted horizontally $20 \mathrm{~cm}$ below the sample holder. Typical Test 1 materials are thin sheets, films, foam blocks, and coatings on end-use substrates or on aluminum foil. Test 1 is analogous in principle to the aviation standard method, FAR 25.853, the 12-second vertical Bunsen-burner test for qualifying insulation batts [5]. For space materials, fire resistance is determined within a closed chamber at the worst-case-use oxygen concentration and pressure environment, currently 30 vol\% oxygen in nitrogen at $70.3 \mathrm{kPa}$ [6]. This atmosphere corresponds to the Shuttle and International Space Station (ISS) environments that are prescribed for crew conditioning prior to extravehicular activities, or that may be encountered as the maximum tolerance level in emergencies.

Test 4, illustrated in Fig. 2, is an adaptation of Test 1 to evaluate the fire resistance of wires or wire bundles under electrical loads. A $31-\mathrm{cm}$ length of wire is mounted at an angle of $15^{\circ}$ from the vertical, a position found to give less interference from combustion products or flow of molten insulation than vertical mounting [7].
Title (Reference ASTM Test)

\author{
Upward Flame Propagation \\ Heat and Visible Smoke Release Rates \\ (Oxygen Consumption (Cone) Calori- \\ meter, ASTM E-1354) \\ Flash Point of Liquids (Pensky-Martens \\ Closed Tester, ASTM D-93) \\ Electrical Wire Insulation Flammability \\ Flammability Test for Materials in Vented \\ or Sealed Containers
}

Upward Flammability of Materials in Gaseous Oxygen

(A comparable test for aircraft wiring insulations is performed at angle of $30^{\circ}$ from the vertical.)

If wire bundles are to be tested, six non-connected wires are cut and laced to the active conductor. The currentcarrying wire is preheated by direct current to an initial temperature of $125 \mathrm{C}$, or to the maximum operating temperature of the wire, for five minutes. Then, the wire is ignited by a chemical igniter or by increasing the internal heating current. The criteria of maximum burn length (visible insulation consumption) prior to self-extinguishment and non-ignition of a paper sheet by hot particles are the same as for Test 1 .

Test 2, illustrated in Fig. 3, determines the ignitability, maximum and average rate of heat release, and amount of smoke obscuration in a standard calorimeter that preheats the samples under a controlled atmosphere by an external heat flux from a conical heater [6]. The samples are ignited by a spark plug, if they do not self-ignite upon preheating. Test 2 is required for major-use nonmetallic panels and as an option for the retest of the flammability of sheet or panel samples failing Test 1.

Test 3 is a standard procedure for determining the flash point of liquids, which is basically the minimum temperature for possible ignition in air. Test 8 is a test for the flammability of otherwise non-acceptable materials contained in protective storage [8]. Test 17 is a test of firesafety performance in oxygen-handling systems, which are critical components in space operations, both internally and externally.

For European spacecraft, fire-resistant items are selected generally through the same testing methods and performance standards prescribed for U.S. spacecraft, with the addition of a limiting-oxygen-index test (ASTM 
D 2863-97) for sheet plastic materials [9]. This test determines downward flame propagation, in contrast to the upward propagation of NASA Test 1; but, in most cases, the criterion of high-oxygen-index will pass and fail the same materials as the criterion of upward-flameextinguishment [10].

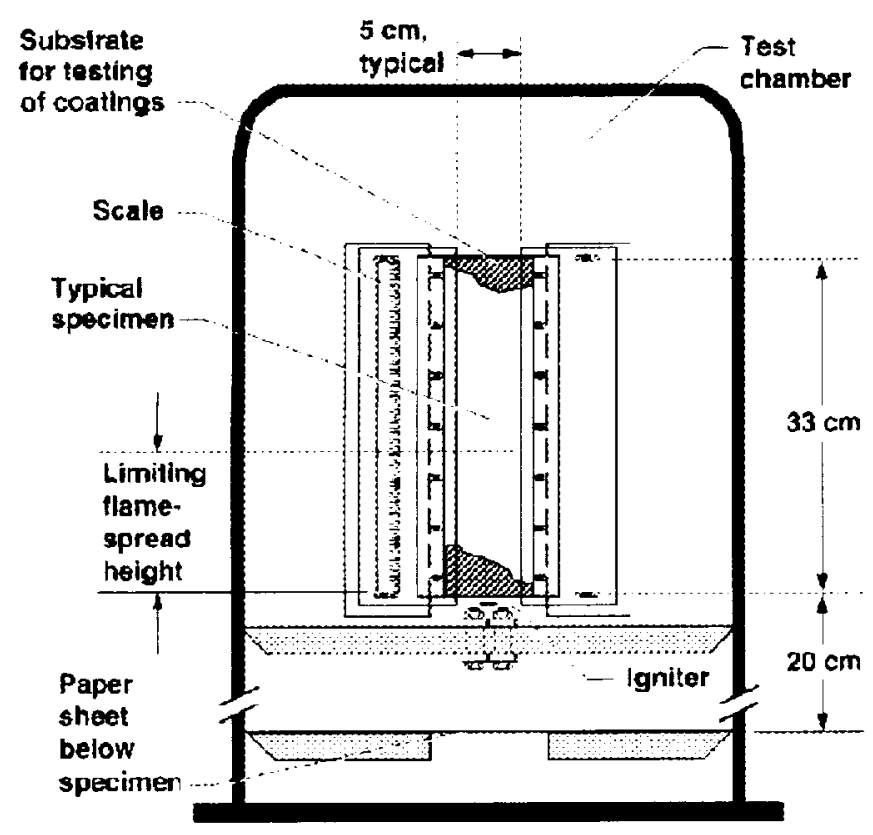

Figure 1. Sketch of apparatus for NASA NHB 8060.1C, Test 1, Upward Flammability Test.

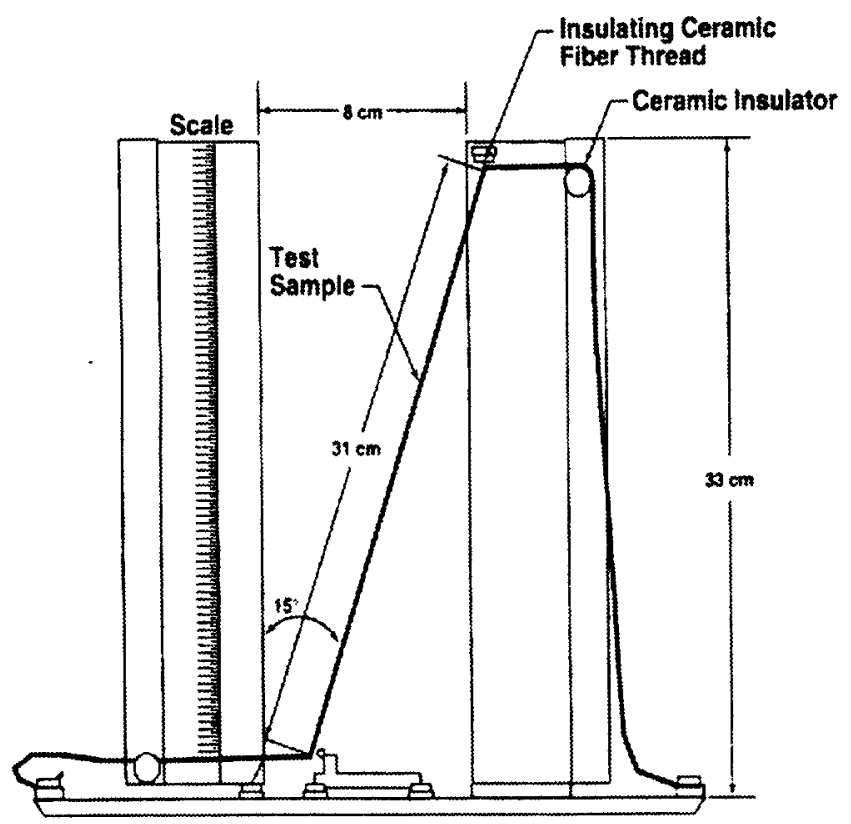

Figure 2. Sketch of apparatus for NASA NHB 8060.1C, Test 4, Electrical Wire Flammability Test.
Upward-flammability assessment offers several advantages in the screening of materials. The NASA Test 1 simulates the beginning of a fire with an ignition flux of typically $75 \mathrm{~kW} / \mathrm{m}^{2}$ maintained for $25 \mathrm{sec}$ [11]. It is a severe "worst-case" test in terms of ignition energy, means of edge ignition, direction of buoyancy-assisted flame spread, sample thickness, and oxygen concentration. Results are rarely ambiguous: samples clearly pass or fail. All assessments are documented by videotaped records for future review. Although Test 1 is basically a qualitative, "pass-fail" evaluation, investigators have shown that, from tests on selected spacecraft materials, there is a linear correlation of the Test 2 rate-of-heatrelease data to the Test 1 flame-spread rate and length of penetration [12].

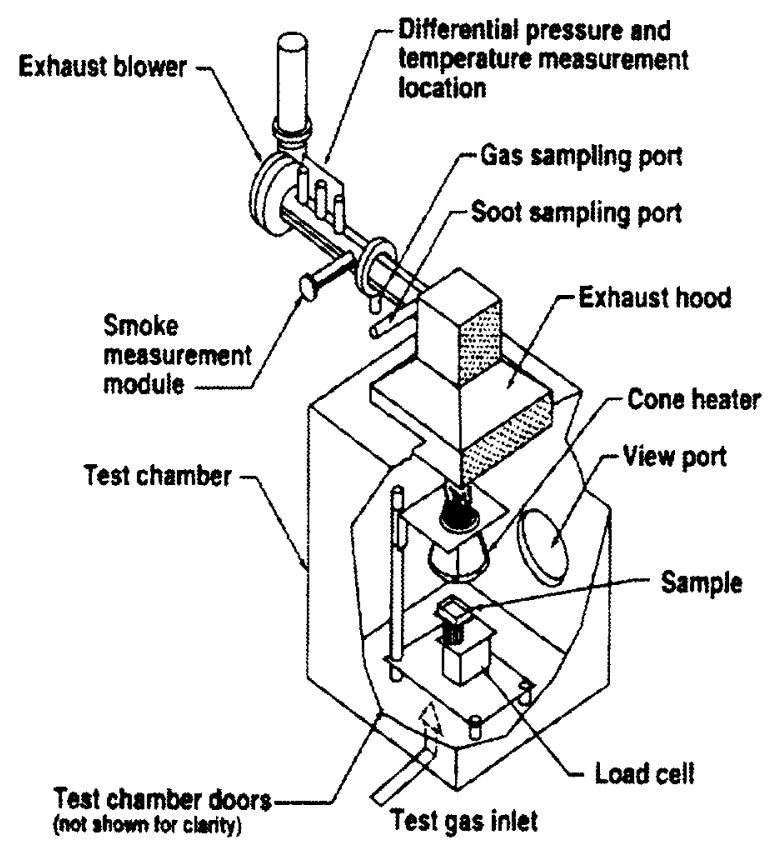

Figure 3. Sketch of apparatus for NASA NHB 8060.1C, Test 2, Heat and Visible Smoke-Release Rates.

More important than whether the standard tests can represent the expected thermal environment in spacecraft fire scenarios is whether the tests can represent the convective environment. In this regard, it is obvious that all practical spacecraft flammability testing, as well as performance and calibration testing of fire-detection and suppression technology, is of necessity conducted on the ground, at normal gravity (the sea-level acceleration of $\left.9.8 \mathrm{~m} / \mathrm{s}^{2}\right)$, not in the environment of the orbiting spacecraft. Still, the use of ground-based test methods and criteria has provided an extensive database of thousands of qualified articles whose fire resistance contributes to the record of effective fire prevention in U.S. space missions [13]. 
Although the great majority of articles for space usage are qualified as fire-resistant, there are many more items, necessary in the spacecraft inventory, that cannot meet the fire performance standards. Common examples are paper, cotton clothing and towels, minor plastic parts, and data films. In addition, there are some essential "off-the-shelf" appliances with components that cannot be verified for fire resistance. The presence and location of these articles are carefully documented before each mission. Techniques to reduce the fire risk of these items include limitation of quantity and spacing, elimination of fire-propagation paths between articles, and storage in non-flammable containers or under nonflammable covers [8].

\section{FIRE PREVENTION BY ATMOSPHERIC SELECTION}

An atmosphere that sustains human life ordinarily supports fire spread. Nevertheless, one can define, in theory, atmospheres that support human life yet inhibit fire spread [14]). One approach is to take advantage of the fact that humans require a minimum quantity of oxygen regardless of the total pressure (within limits), but fires require a minimum concentration of oxygen in the diluted atmosphere $[15,16]$. Thus, an atmosphere modified through nitrogen pressurization retains a sea-level oxygen partial pressure for life support, with a reduced oxygen concentration to prevent fire spread. A typical atmosphere meeting this criterion is one with a concentration of 13.9 vol\% oxygen at a total pressure of $151 \mathrm{kPa}$ [17]. This total pressure, however, is far beyond the usual spacecraft structural limits.

An alternative fire-inhibiting atmosphere is one with the oxygen quantity reduced to a minimum for life support, but with no change in total pressure [18]. An oxygen partial pressure equivalent to that of a pressure altitude of $2400 \mathrm{~m}(8000 \mathrm{tt})$ produces a concentration of $15.6 \%$, if the total pressure remains at $101 \mathrm{kPa}$. This is actually a minimum off-normal environment permitted in the U.S. spacecraft requirements. The oxygen concentration in this atmosphere may not be low enough to prevent ignition and flame spread in all materials, however.

Since the atmosphere within the spacecraft is entirely controllable, other diluents with differing thermal characteristics may be substituted for all or part of the nitrogen. Medical and combustion specialists have suggested oxygen-diluent atmospheres that can sustain life yet inhibit flame spread [19]. None of the "fire-safe"atmosphere proposals is a serious contender for even preliminary research, however. One argument against unconventional atmospheres is the need for reference air atmospheres for biological and medical experiments in space [18]. More compelling negative arguments are the logistic and structural impacts of gas-pressure and gasstorage changes and the unknown effects of long-term exposure to modified atmospheres on the crew perform-

NASA/TM-1999-209285 ance and health under the stressful conditions of space operations [20].

\section{THE INFLUENCE OF LOW GRAVITY ON FIRE BEHAVIOR}

\section{IGNITION PROCESSES IN MICROGRAVITY}

Practical fire prevention and control in orbiting and planetary-transit spacecraft must respond to the unique effects of the non-convective, low-gravity environment (microgravity) on fire initiation [21]. For example, overheated motors, bearings, and other components will remain hot because of the minimal convective heat transfer in microgravity, and they can present serious ignition threats for a long time. Again, spills or line breaks can create aerosols or particle clouds that persist indefinitely in microgravity because of the lack of densitydriven settling. These heterogeneous arrays are known to be highly flammable. Furthermore, recent research shows that, if ignition occurs, the resulting peak explosion pressures in these mixtures are stronger in microgravity than in normal gravity, due to the uniform and stable composition of the aerosols in microgravity [22].

The absence of downward motion also contributes to the hazards from effervescing or easily vaporized materials, which tend to eject hot bubbles or drops when ignited. These globules can drip harmlessly in normal gravity, but they propel radially as potential ignition sources in low gravity $[23,24]$.

\section{FIRES IN QUIESCENT AIR IN MICROGRAVITY}

It is generally assumed that materials qualified as fireresistant in ground testing will be equally or more fire resistant in microgravity service. Early studies of the combustion of sheet samples of common spacecraft materials (e.g., paper, plastics, cotton, aluminized Mylar) in static-chamber tests conducted on the Skylab space station showed that, in all cases, the observed flamespread rates are slower than the corresponding rates on the ground [25]. The relationship of flame-spread rates measured in low gravity to those in normal gravity is unique for each material, and no quantitative correlation of gravity effects can be obtained from these tests. Subsequent research on the combustion of thin-sheet materials, conducted in a variety of low-gravity venues, such as drop towers, parabolic-trajectory airplanes, the Shuttle, and Mir, has confirmed these qualitative findings. Moreover, these results show that, for thin solid fuels burning in non-flow (quiescent) microgravity environments, the flammability range (minimum oxygen concentration) is reduced, the fuel mass-loss rate is less, the flame temperature is lower, the rate of heat release is lower, and the soot production is reduced, as compared to the corresponding qualities in normal-gravity combustion [26-28]. For thick sheet materials burning in nonflow microgravity environments, the flame-spread rate 
decreases with time and the flame tends to self-extinguish, although combustion may persist several minutes [29].

There are a few exceptions to the generalization that flammability is reduced in quiescent microgravity. Metal wires may burn more rapidly in high-oxygen environments in space than on Earth, because the molten droplet does not detach from the flame zone and drip away [30]. Recently reported studies show greater rates of flame spread in microgravity for vertical burning wire insulations, although the wires themselves may have served as a heat source or sink, complicating the interpretation of these results [31]. The situations where flammability may be accelerated in quiescent microgravity appear to be rare, and they correspond to very unusual scenarios for potential spacecraft fire events.

\section{FLOW-ASSISTED FIRES IN MICROGRAVITY}

The mitigation of fire severity, as compared to the corresponding normal-gravity behavior, occurs only in non-flow conditions in microgravity. This quiescent flame environment is unique to microgravity. Normal-gravity flames generate strong, gravity-driven buoyant currents, due to density differences between the combustion gases and the surrounding atmosphere. These currents aid the combustion reaction and the flame spread by removing combustion products and introducing ambient oxygen into the flame zone. The lack of natural-convective flow in microgravity is the principal cause of the relatively weak flames.

In actuality, except in closed combustion chambers, spacecraft atmospheres are not quiescent. Ventilation for atmospheric conditioning and component cooling provides a continuous flow environment. Typical humancrew spacecraft are designed to maintain a comfortable atmospheric circulation at low superficial velocities, over a nominal range of 6 to $20 \mathrm{~cm} / \mathrm{s}$. Combustion research now observes that, at least for thin cellulosic fuels, the addition of low-velocity forced flow greatly increases the microgravity flame spread. In fact, the flow-promoted microgravity flame-spread rates may exceed those in comparable downward flame spread in normal gravity (but not those in buoyancy-promoted upward flame spread) [21]. Equally important, the flammability range, defined by the limiting oxygen concentration for flame spread, with a slow, forced flow in microgravity is greater than that in corresponding downward spread [32] and approximately equal to that for upward spread in normal gravity [33].

In the usual combustion test, ignition is at one end of a strip sample, and the flame can propagate only in the direction of the unburned fuel, regardless of the air-flow direction. Tests on thin cellulosic fuels with central ignition show that the microgravity flame will propagate preferentially into the flow, or in the opposed (upstream) direction [34]. This behavior occurs because the oxygen is completely consumed in this direction and is unavailable downstream. This observation is clearly the reverse of common experience in normal gravity, where flow promotes the flame in the concurrent (downstream) direction [35].

The addition of low-velocity flow is also shown to sustain flame spread over thick sheet materials in microgravity, which, as noted, tend to self-extinguish under quiescent conditions [36]. Similarly, wire insulations usually resist flame spread in quiescent microgravity but burn readily under low air velocities [37]. For smoldering, recent studies report that propagation through bulk polyurethane foam is sustained in microgravity by minimum velocities as low as $1 \mathrm{~mm} / \mathrm{s}$ [38].

\section{OXYGEN-ASSISTED FIRES IN MICROGRAVITY}

The Mir fire in February 1997, caused by the failure of a solid-oxygen generator, is a good example of the difficulty in predicting potential fire scenarios in spacecraft. The Mir fire propagated in a highly convective local environment, at an elevated oxygen concentration, self-generated by the source of the fire. It is no surprise that these conditions favor rapid flame spread even in microgravity. Drop-tower studies on thin-paper samples, illustrated in Fig. 4, show that flame-spread rates increase with oxygen concentration in quiescent microgravity and approach those values obtained in downward normal gravity at concentrations of $40 \%$ and greater [39]. Airplane studies on thin polymethylmethacrylate (PMMA) samples show similar, substantial increases in spread rates with increasing oxygen concentration; but, in this case, the low-gravity rates are always less that those in normal gravity, even at oxygen concentrations as high as $90 \%[24]$.

A series of Shuttle tests, the Solid Surface Combustion Experiment (SSCE), provided quantitative data on the effects of atmospheric oxygen concentration and total pressure on thin-paper flame spread in quiescent microgravity [27]. A summary of flame-spread rate determinations is shown in Fig. 5. (Each data point represents the results from a separate Shuttle mission.) The increase in oxygen concentration from 35 to $50 \%$ increases the flame-spread rates by factors of three to four. The twofold increase in total pressure also increases the flamespread rate by a factor of about 1.5 (for the $50 \%-\mathrm{O}_{2}$ concentration).

For thick materials, the effect of increasing oxygen concentration is qualitatively similar to that on thin materials. The SSCE program included tests on relatively thick strips of PMMA at oxygen concentrations of 50 and $70 \%$. As noted earlier, in the quiescent atmosphere, the flamespread rate is not uniform, but plots of flame position with time clearly show that the level of flame propagation is 
much more rapid at $70 \% \mathrm{O}_{2}$ at all stages of the combustion [29].

\section{DILUENT-MODIFIED FIRES IN MICROGRAVITY}

The influence of the diluent component of the quiescent microgravity atmosphere on fires has been studied for cases of

1. the inclusion of combustible gases (at concentrations below the lower flammability limit of the additive), or

2. the replacement of the usual nitrogen diluent with other inert gases.

The presence of combustible gases in the spacecraft atmosphere is a possible consequence of such breakdown events as leakage, pyrolysis, or decomposition. The replacement of nitrogen by other inertants may be intentional for purposes of life support or for fire inhibition.

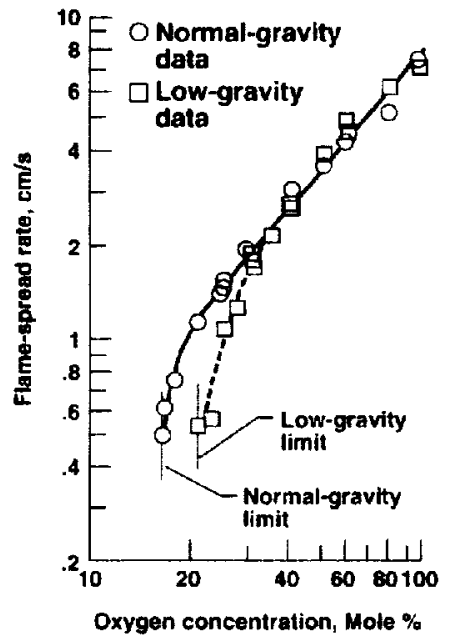

Figure 4. Experimental data on flame-spread rates and flammability limits of thin-paper fuels for downward normal gravity and quiescent microgravity [39].

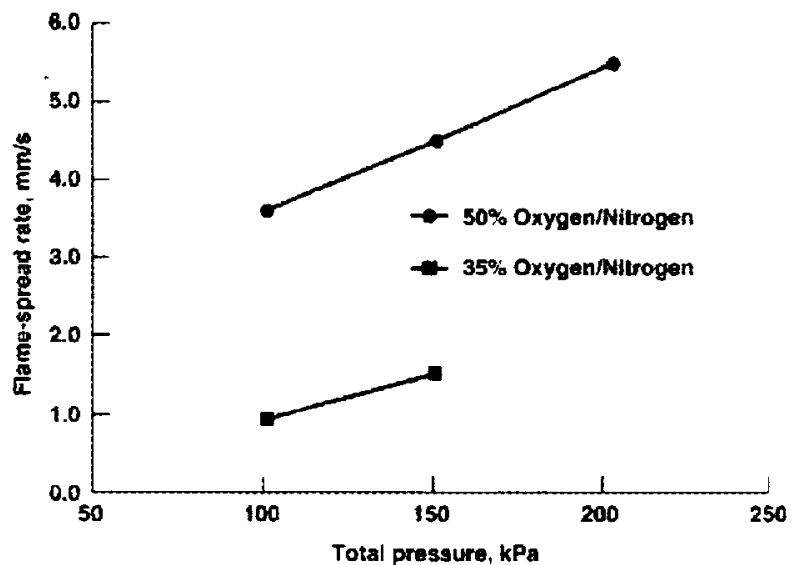

Figure 5. Experimental data on flame-spread rates in quiescent microgravity, from Solid Surface Combustion Experiment [27].
Recent results from tests on the flammability and flame spread of thin cellulosic fuels in diluent-modified atmospheres are most interesting. For the inclusion of combustible gases, the remarkable finding is that low concentrations of carbon monoxide or methane in air increase the flame-spread rate in proportion to the fuelgas concentration and this influence is stronger in microgravity than in normal gravity [40]. In fact, at higher concentrations of carbon monoxide, the microgravity flame-spread rates exceed those in corresponding normal gravity.

For the replacement of nitrogen diluent, the tests show that, for nitrogen, helium, or argon dilution, the flamespread rate and flammability range are reduced in microgravity compared to normal gravity. (Selected data are in Table 2.) For carbon-dioxide dilution, the gravity effects are slight, but for sulfur-hexafluoride dilution, the flame-spread rate and flammability are substantially increased in microgravity. On the other hand, the absolute levels of flame-spread rate and flammability with these gases are still well below those of the other diluents in both environments, and the gases act basically as flame suppressants $[40,41]$.

\section{MATERIAL-ASSESSMENT TESTS FOR MICROGRAVITY USAGE}

Applied experimental combustion studies are now underway, aiming at systematic measurements of flame spread over practical materials in ventilated microgravity. One such project measures flame-spread rates over cylindrical plastic specimens with controlled air flow in a Russian flow-tunnel facility operated on Mir. Another project, Diffusive and Radiative Transport in Fires (DARTFire), also measures flame spread over thick PMMA sheets in a combustion tunnel operated on sounding rockets. DARTFire incorporates imposed flow, atmospheric control, and radiant heat flux as variables in the experiments [42].

Research projects are also investigating test methods to predict fire resistance in space based on modifications or correlations of normal-gravity assessments [43]. A study in progress is developing a new ignition-delay and flamespread test incorporating external heat flux and low-velocity flow as part of the flammability-test routine [44].

Combustion specialists are aware of the difficulty in reproducing the flow and energy fields in the microgravity environment for these material-qualification assessments. It is thus unlikely that any single test method will ever be found that is capable of characterizing material acceptability for all incipient-fire scenarios in space [45]. 
Table 2. Flammability of Thin Cellulosic Sheet Fuels Under Atmospheres with Varying Diluents (from [40])

\begin{tabular}{|c|c|c|c|c|c|}
\hline Diluent $\rightarrow$ & $\begin{array}{l}\mathrm{N}_{2} \\
\quad \mathrm{NO}\end{array}$ & $\begin{array}{l}\mathrm{He} \\
\text { IAL GF }\end{array}$ & $\begin{array}{l}\text { Ar } \\
\text { VITY }\end{array}$ & $\mathrm{CO}_{2}$ & $\mathrm{SF}_{6}$ \\
\hline $\begin{array}{l}\text { Flammability } \\
\text { Limit, } \% \mathrm{O}_{2}:\end{array}$ & 16 & 16.5 & 11.5 & 24 & 38 \\
\hline $\begin{array}{c}\text { Flame-Spread } \\
\text { Rate, cm/s: } \\
\text { at } 20 \%-\mathrm{O}_{2}\end{array}$ & 0.9 & 1.8 & 1.9 & $\cdots$ & --- \\
\hline at $25 \%-\mathrm{O}_{2}$ & 1.3 & 2.7 & 3.0 & 0.5 & -- \\
\hline at $30 \%-\mathrm{O}_{2}$ & 1.7 & 3.5 & 4.1 & 1.2 & -- \\
\hline at $35 \%-\mathrm{O}_{2}$ & 2.2 & 4.3 & & 1.7 & --- \\
\hline at $40 \%-\mathrm{O}_{2}$ & 3.0 & 5.0 & & 1.9 & 0.45 \\
\hline at $45 \%-\mathrm{O}_{2}$ & & & & 2.3 & 0.95 \\
\hline
\end{tabular}

\section{QUIESCENT MICROGRAVITY}

Flammability

Limit, $\% \mathrm{O}_{2}$ :

17

Flame-Spread

Rate, cm/s:

at $20 \%-\mathrm{O}_{2}$

at $25 \%-\mathrm{O}_{2}$

at $30 \%-\mathrm{O}_{2}$

at $35 \%-\mathrm{O}_{2}$

at $40 \%-\mathrm{O}_{2}$

at $45 \%-\mathrm{O}_{2}$

\section{FIRE DETECTION IN SPACE ENVIRONMENTS}

\section{STATUS OF FIRE DETECTION IN SPACECRAFT}

In the five fire-precursor incidents experienced in more than 18 years of Shuttle Transportation System missions, the crew detected the problems by odor and sight and responded by isolating and deenergizing the affected electrical circuits [13]. In the most serious incident, a cable strain and insulation failure created an electrical short circuit, which caused the expulsion of embers and particles [46]. That incident resulted in an estimated maximum particle concentration of only one-tenth of the alarm setting, and consequently the smoke detectors did not alarm.

Thus, sensing by the crew can be relied on for the early warning of incipient fires in spacecraft; and, in the first U.S. human-crew space missions (Mercury, Gemini, and Apollo), this was the only means of fire detection. The first automated fire detectors installed in spacecraft were those in the 1974 Skylab space station, which had a collection of 30 radiation detectors sensitive to fire-generated emissions in the ultraviolet spectrum. This type of detector is a line-of-sight sensor, and it responds to already established fires.

All human-crew spacecraft subsequent to Skylab have been equipped with smoke detectors, which have the advantages of generalized sampling and high sensitivity to smoke particulates emitted not only from incipient fires but also from smoldering and pyrolysis events [47]. Smoke detectors sense the buildup of particles in the atmosphere by several means, including ionizationcurrent interruption, photoelectric scattering and obscuration, quartz-crystal microbalance response, or condensation-nuclei counting. Detectors employing the first two principles, ionization and photoelectric, have been adapted for practical service onboard spacecraft; and, indeed, these are the types found in almost all commercial smoke detectors on Earth. 


\section{CURRENT FIRE DETECTION FOR SPACECRAFT}

The ionization detectors of the Shuttle and its payloadbay laboratories (Spacelab, for example) are the first smoke detectors designed specifically for installation in spacecraft [48]. An aerodynamic separator causes particles larger than about $2 \mu \mathrm{m}$ (dust, perhaps) to bypass the ionization chamber. The flow through the inlet separator and the sensing chambers is created by an internal fan, a vane pump, which may also promote the sampling effectiveness in the non-convective environment, although the manufacturer states that the fan is solely for particle separation [49].

The photoelectric detectors of the pressurized modules of the International Space Station (ISS) utilize the principle of attenuation or scattering of light by smoke particles [50]. The scattering measurement is the primary source for the alarm circuitry. The obscuration signal is used for built-in tests and zero-drift adjustments [51]. The long-wave-length visible light source makes these detectors most sensitive to particles larger than $0.3 \mu \mathrm{m}$ in size.

The Shuttle and ISS detection systems are not identical because they have different design requirements and must meet varied constraints, such as allotted power, volume, functionality, senviceability, and useful lifetime. For operation on the ISS, the photoelectric detector has recognized advantages over the Shuttle ionization type in its much lower power requirement, slightly lower mass, and lack of moving parts [48].

On Earth, smoke detectors are located on ceilings because buoyancy carries the particle-laden air upward first before spreading down to the floor. In the absence of buoyancy, detector location is less certain. On the Shuttle, detectors are located in ventilation paths in the avionics bays and the flight decks. On the ISS, detectors monitoring the equipment racks within each module will be installed with their light paths directly within cooling-air return pipes, or exposed to the general air-circulation flow. The ISS modules supplied by the U.S., European, Japanese, and Italian space agencies have identical fire prevention, detection, and suppression requirements and operations [52]. Because the elements of the Russian segment have been designed independently and in some cases prior to the designs of the ISS, they have different fire-response systems. The Functional Cargo Block (Zarya), the first assembly element of the ISS, placed in orbit on November 1998, has ten ionization smoke detectors, similar in principle to those on the Shuttle [53]. The Service Module, the primary Russian element, to be launched on the third assembly mission, has photoelectric detectors, of the type used in Mir.

\section{LOW-GRAVITY PERFORMANCE}

The overall reliability of the Shuttle detectors has been high. Through almost 100 Shuttle missions, covering over $18,000 \mathrm{hr}$ of orbital operations, there have been less than 15 reported false alarms or built-in-test failures.

Criteria for alarm thresholds are established for the ionization and photoelectric smoke detectors from testing and calibrations against model fires in normal gravity [48]. For performance in microgravity, however, there are concerns over the possible slow response and low sensitivity of detectors to the nearly invisible flames with little apparent smoke, as observed in quiescent and lowflow conditions [54]. Furthermore, the criteria for sensitivity and false-alarm rejection of the smoke detectors depend on foreknowledge of the size and size distribution of the particles released in a fire event. Limited experiments in low gravity indicate that particulates tend to be larger than in normal gravity in the early stages of a fire (Fig. 6), most likely because the lack of convective movement favors the agglomeration of individual particles [55].

A science experiment on the Shuttle, Comparative Soot Diagnostics, investigated the effluent-particle sizes generated by overheated wiring insulation, pyrolyzing silicone rubber, burning paraffin, and burning paper in a slow-moving air stream [56]. The experiment also exposed a Shuttle detector unit and an ISS detector prototype to the particulate-air stream a few meters downstream of the sources to determine the sensitivity and response of the detectors in microgravity. Fig. 7 is a selection of the results for one of the tests to illustrate the detector responses following the pyrolysis of polyimideinsulated wiring. The igniter that promoted the pyrolysis event was turned on for a period of about $20 \mathrm{sec}$. The scattering signal of the ISS photoelectric detector actuated first, reaching full scale at about 20 -sec elapsed time, during the period when the igniter was still on. The signal of the prototype ISS unit was amplified because of a low signal level from what is now known to be a defective early model. The Shuttle ionization detector actuated about 20 seconds later, with its characteristic signal of a distinct decrease from full scale, which should trigger an alarm circuit, then a gradual return to the original value. Both detectors responded adequately, in the illustrated manner, to most pyrolysis, smoldering, and flaming events (allowing for the amplification of the ISS signal), with delays of the order of 10 to $70 \mathrm{sec}$ to reach an assumed actuation level. The Shuttle detector, however, did not attain a significant signal level for liquid smoke particulates from smoldering paper and silicone rubber. The important qualitative conclusion of the study is that the relative responsiveness of these detectors is different in microgravity compared to normal gravity, most likely due to the differences in particle sizes and morphology. 

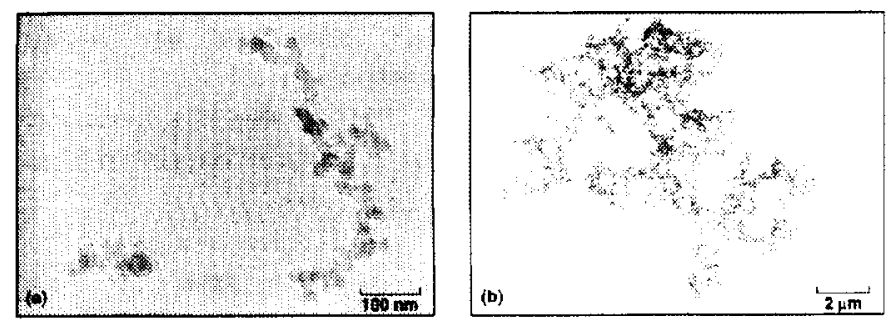

Figure 6. Examples of soot particles collected over ethylene diffusion burners (note differing scales of magnification). (a) Normal gravity. (b) Low gravity.

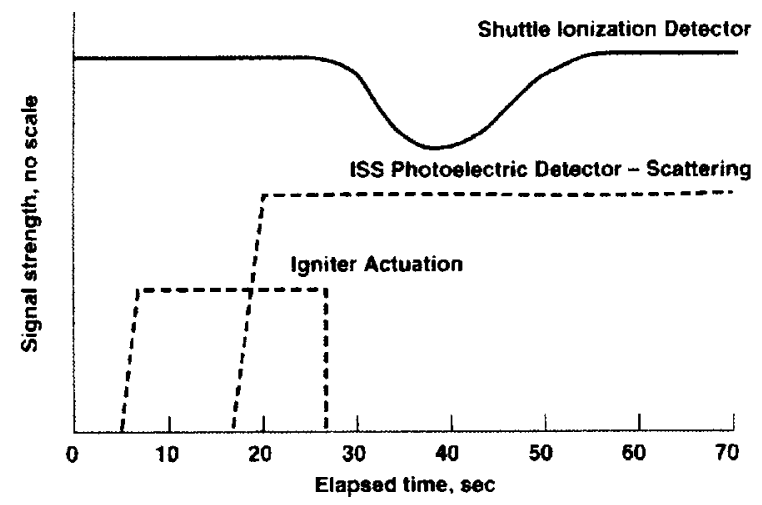

Figure 7. Time sequence of ignition events and detector responses following pyrolysis of polyimide wire insulation, from Comparative Soot Diagnostics Experiment [56].

\section{RADIATION AND GAS DETECTION}

The original designs of the ISS also included flame-radiation sensors for overall monitoring of the modules and some of the enclosed standoff and rack volumes within the modules [51]. The need to conserve mass and electric power eliminated these detectors from the ISS designs, but technology development continues in the European Space Agency on flame detectors for supplementary fire detection [57].

Discrete sampling of the spacecraft atmosphere for trace constituents, particularly carbon monoxide, can also provide early warning of incipient fires or smoldering [58]. Active development is underway on continuous analysis systems for the ISS [59]. Gas sensing for fire detection has advantages of rapid, sensitive, but non-localized response. A promising concept for the future is that of combined detection systems, with multiple logic responding to both carbon monoxide and smoke, if these can be accommodated within the spacecraft mass and power allowances [60].

\section{FIRE CONTROL AND SUPPRESSION IN SPACECRAFT}

\section{STATUS OF FIRE SUPPRESSION ON SPACECRAFT}

Spacecraft have always been equipped with fire extinguishers as protection against spreading fires [61]. In the Mercury and Gemini spacecraft, a water gun used for food reconstitution was designated for the secondary purpose of an emergency fire extinguisher [62]. The next generation of space missions was equipped with dedicated fire extinguishers. The Apollo spacecraft, for example, had foam-based extinguishers, which generated a stable water-gas mixture propelled by inert Freon and nitrogen gases. At present, the agents of choice for spacecraft are compressed gases, with exceptions to be noted.

\section{CURRENT REQUIREMENTS AND PRACTICES}

In the Shuttle, if a fire is detected in the cabin, the expected crew response is to turn off the cabin fan, don the protective helmets (part of the launch and entry suits), and discharge a portable fire extinguisher. If a fire is detected in an equipment rack or an avionics bay, the expected crew response is to deenergize the affected circuits or the entire rack, then also don the protective helmets, and discharge a portable fire extinguisher. The rack covers have circular holes (fire ports) for insertion of fire-extinguisher nozzles to flood the interiors. The Shuttle crew also has the option of fire fighting through the discharge of extinguisher bottles mounted in the cabin and in each avionics bay, actuated by control-panel switches. The availability of the fixed suppression system on the Shuttle is essential to safety, because during reentry, the crew is immobile and has no access to the portable fire extinguishers.

The ISS will have portable extinguishers only. After the Phase II assembly is complete, the station will always have a mobile crew on hand; hence the added complexity of a fixed system is not necessary [63]. The ISS extinguisher will have two interchangeable nozzles: one, a cone for streaming application in open areas, and the other, a tube for flooding application by insertion into a rack fire port. Each rack closure will have a membraneprotected fire port to permit internal flooding of the rack by insertion of the extinguisher nozzle, as in the Shuttle. Upon a verified alarm, software will shut down cabin ventilation within the affected module and remove local electrical power at the fire location within 30 seconds. The ISS suppression system is designed to release sufficient agent to reduce the ambient oxygen in a local affected volume to half the original concentration within 60 seconds [52]. A module can also be isolated from the rest of the ISS complex by closing valves to cut off the intermodule ventilation. 


\section{FIRE-EXTINGUISHING AGENTS}

The Shuttle and its payload-bay laboratories have extinguishers charged with gaseous Halon 1301 (bromotrifluoromethane). The manufacture and new uses of Halon 1301, which has a high ozone-depletion potential, are now prohibited by international protocol [64]. Existing installations such as those on the Shuttle may be retained indefinitely. Halon 1301 is an extremely efficient fire extinguisher, chemically inhibiting the combustion reactions. Concentrations of no more than $6 \%$ are sufficient to extinguish most fires, except perhaps some that are deep-seated. Halon 1301 does generate toxic and corrosive products, but in standard discharge rates, the product concentrations are very low. Shuttle flights may continue if the measured trace-product contamination following an extinguisher discharge is within the spacecraft maximum allowable concentrations. Early mission termination and return to ground is, of course, an option to ensure safety on the Shuttle.

The ISS will have extinguishers charged with carbon dioxide in all its segments except for those in the Russian segment (developed independently), which will have water-based foam extinguishers [63]. Carbon dioxide has been selected through trade-off studies, which compare weighted attributes of competing agents for spacecraft application. Carbon dioxide has advantages in its low cost, availability, reliability, and absence of halogenated products. It is a relatively inefficient agent, since its action is by oxygen dilution, requiring as much as $50 \%$ $\mathrm{CO}_{2}$ concentrations in local volumes. Leakage may generate excessive, toxic atmospheric concentrations, difficult to remove by the standard ISS environmentalcontrol system [65].

Nitrogen is under consideration for suppression protection in small, attended volumes, such as the airlock of the ISS. Nitrogen avoids the toxicity issue of carbon dioxide, although it is even less efficient as a suppression agent [66].

Mixed-phase, water-based foams and mists are supplied to the ISS Russian segment, as noted. These non-gaseous agents can be very effective, providing suppression through flame cooling as well as oxygen dilution [67]. The liquid foam residues, however, are very difficult to remove from the spacecraft atmosphere and surfaces after fire control.

\section{LOW-GRAVITY PERFORMANCE}

The initial step in fire response is the shutoff of local and, in some cases, module air circulation. As discussed in a previous section, research has demonstrated that fires over solid surfaces in microgravity tend to self-extinguish when flow ceases. It is unknown, however, whether an established fire of more than minimal size can be controlled merely by removal of air flow. In spreading fires, the expansion of the combustion gases and the expulsion of fuel particles may generate enough force to promote flow even in microgravity. Hence, fire suppression by extinguishing agents is likely to be an essential response to all but minor, incipient fires.

The microgravity environment may have little influence on the process of extinguishment in flooding applications, as within racks. Low gravity, however, will likely affect streaming applications, perhaps making the physical application more difficult and the rate of dispersion slower. Clearly, the discharge of non-gaseous, mixedphase agents will require new techniques in low gravity, since these agents depend on downward settling, a gravity-aided process, to cover burning surfaces or liquid pools. The Skylab tests examined the effect of water sprays on burning samples in a chamber [25]. The spray broke up into isolated droplets. Only a few droplets struck the burning material, and they tended to scatter the flaming material before extinguishing the flame. More recent tests on an airplane flying parabolic trajectories demonstrated the effective dispersion of water and foam in low gravity, albeit in non-burning tests [68].

Researchers are particularly concerned with the relative efficiency of fire suppression in microgravity. Results of small-scale tests in drop towers, investigating the effect of dilution of the atmosphere by suppressants on the ignition and flame spread of thin fuels, are encouraging. For Halon-1301 dilution, the quantity needed for suppression is shown to be appreciably less in microgravity than in corresponding normal gravity [62]. For carbondioxide dilution, suppression effectiveness is also indicated by reduced flammability compared to air or nitrogen-oxygen reference cases [41]. These tests, however, cannot demonstrate diluent effectiveness for the scenario of extinguishment of an established, spreading fire in ventilated microgravity.

\section{FIRE FIGHTING AND POST-FIRE ACTIONS}

The ISS has the option of abandoning a module, closing its hatches, and venting the module, as a means to control a difficult or inaccessible fire. Proposed venting capability is the attainment of a total pressure of $30 \mathrm{kPa}$ or less within 10 minutes [52]. The limit is arbitrary, based on a compromise rate of venting. Slow depressurization delays suppression, but rapid depressurization may cause flame intensification prior to suppression [25]. Results of recent small-scale research on venting extinguishment in low gravity offer a new venting criterion [69]. The studies indicate that the pressure limit for suppression by venting under normal or low gravity is a function primarily of the fuel temperature. This information suggests that rapid venting is most desirable in microgravity, with the target total pressure reduced to as low as $10 \mathrm{kPa}$. 
The determination of the completion of fire extinguishment in spacecraft is by no means straightfonward. Since burned material remains hot in the non-convective environment, embers may reignite if prematurely exposed to fresh air [70]. The Shuttle regulations permit the crew to determine the fire cessation by observation, but they also note that the smoke detector reading should be stable or decreasing. For a fire in a closed avionics bay, if the local power is off and an extinguisher bottle is discharged, the fire is considered suppressed. Corresponding fire-cessation criteria for the ISS are still under review [71].

Considerable cleanup will be required after all fire events, minor or major [72]. Atmospheric revitalization to remove even trace quantities of fire and extinguishment contamination may tax the environmental-control system and require the use of portable crew breathing equipment and filters for periods of time. On a longer time scale, the subtle toxic and corrosive aftereffects of the fire on equipment, systems, and payloads must be recognized and appropriately controlled [2].

\section{CONCLUDING REMARKS}

The record of fire safety on the Shuttle confirms the adequacy of the current fire-prevention policies and practices. The major premise of fire prevention is the qualification of materials as fire-resistant. It is, of course, impractical to test even a small, representative sampling of materials in microgravity. The standard normal-gravity tests, in which the modeled flame propagation and extinction mechanisms are distinctly different from those in low-gravity flames, are regarded as "worst-case" representations. This implied margin of safety is known to decrease when applied to materials under typical microgravity environments with forced gas flows or at sufficiently elevated oxygen concentrations.

Quantitative data relating combustion behavior in ventilated microgravity to that in corresponding normal gravity are scant. Consequently, research is aimed at an understanding of low-gravity flammability in order to develop test protocols and predictive correlations to contribute to the continued improvement of spacecraft fire prevention, detection, suppression, and recovery.

\section{CONTACT}

The author is a senior aerospace engineer in the Microgravity Combustion Science Branch, Mail Stop 500-115, of the NASA Glenn (formerly Lewis) Research Center. He may be reached at $216-433-5697$ by voice telephone or by E-mail at Robert.Friedman@grc.nasa.gov.

NASA/TM-1999-209285

\section{REFERENCES}

1. Kaplan, S.: Safety Risk Assessment on the Space Station Freedom. AIAA Paper 90-3771, Sept. 1990.

2. Friedman, Robert: Fire Safety in Spacecraft. Fire and Mater., vol. 2, 1996, pp. 235-243.

3. Sawyer, C.R.: Space Station Freedom Secondary Power Wiring Requirements, in Hammoud, Ahmad; and Stavnes, Mark W., eds.: First NASA Workshop on Wiring for Space Applications. NASA CP 10145, Sept. 1994, pp. 99-113.

4. NASA Office of Safety and Mission Quality: Flammability, Odor, Offgassing, and Compatibility Requirements and Test Procedures for Materials in Environments That Support Combustion. NASA NHB 8060.1C, April 1991.

5. Cahill, Patricia: Evaluation of Fire Test Methods for Aircraft Thermal Acoustical Insulation. DOT/FAA/AR-97/58, Sept. 1997.

6. Hsieh, Fu-Yu; and Beeson, Harold D.: Evaluation of the Controlled-Atmosphere Cone Calorimeter for Determining Fire Properties of Materials According to NASA Handbook 8060.1C Test 2. NASA TM 104809, Dec. 1995.

7. Rodak, E.M.; Taylor, Ronald J.; Hirsch, David B.; and Linley, Larry J.: Effects of Sample and Test Variables on Electrical Wire Insulation Flammability. Jour. Testing and Eval., vol. 22, 1994, pp. 449-452.

8. Nicholson, Leonard S., ed.: Flammability Configuration Analysis for Spacecraft Applications. NASA Johnson Space Center NSTS 22648, Oct. 1988.

9. ESTEC Materials and Processes Div.: Flammability Testing for the Screening of Space Materials. ESA PSS-01721, Issue 2, April 1992.

10. Hirsch, D.: Comparison of Results of the European Space Agency Oxygen Index Test and the NASA Upward Propagation Test. NASA JSC White Sands Test Facil. TR-581001, March 1989.

11. Hsieh, Fu-Yu; and Beeson, Harold D.: Flammability Testing of Flame-Retarded Epoxy Composites and Phenolic Composites. Fire and Mater., vol. 21, 1997, pp. 41-49.

12. Hsieh, Fu-Yu; and Beeson, Harold D.: Cone Calorimeter Testing of Epoxy/Fiberglass and Brominated Epoxy/Fiberglass Composites in Normal Oxygen and Enriched Oxygen Environments, in Janoff, Dwight D.; Royals, William T.; and Gunaji, Mohan V., eds.: Flammability and Sensitivity of Materials in Oxygen-Enriched Atmospheres, 7th Vol. ASTM STP 1267, ASTM, West Conshohocken PA, 1995, pp. 152-167.

13. Friedman, Robert: Risks and Issues in Fire Safety on the Space Station. NASA TM 106430, March 1994.

14. Sacksteder, Kurt. R.: The Implications of Experimentally Controlled Gravitational Accelerations for Combustion Science. Twenty-Third Symp. (Inter.) on Comb., The Comb. Inst., Pittsburgh, 1991, pp. 1589-1596.

15. Huggett, Clayton: Habitable Atmospheres Which Do Not Support Combustion. Comb. and Flame, vol. 20, 1973, pp. 140-142.

16. West, John B.: Fire Hazard in Oxygen-Enriched Atmospheres at Low Barometric Pressures: Aviation, Space, and Envir. Med., vol. 68, 1997, pp. 159-163.

17. Law, C.K.: Combustion in Microgravity: Opportunities, Challenges, and Progress. AIAA Paper 90-0120, Jan. 1990.

18. Shvartz, E.: Advantages of a Low-Oxygen Environment in Space Cabins. Aviation, Space, and Envir. Medicine, vol. 1, 1990, pp. 270-276.

19. Knight, Douglas R.: Medical Guidelines for Protecting Crews with Flame-Suppressant Atmospheres. SAE Tech. Paper 891596, July 1989.

20. Knight, Douglas R.: The Medical Hazards of Flame-Suppressant Atmospheres. Naval Submarine Med. Res. Lab Rept. 1167, April 1991. 
21. Friedman, Robert; and Urban, David L.: Contributions of Microgravity Test Results to the Design of Spacecraft Fire-Safety Systems. AIAA Paper 93-1152, Feb. 1993.

22. Pu, Y.; Podfilipski, J.; and Jarosinski, J.: Constant Volume Combustion of Aluminum and Cornstarch Dust in Microgravity. Comb. Sci. and Technol., vol. 135, 1998, pp. 255267.

23. Olson, Sandra L.; and Sotos, Raymond, G.: Combustion of Velcro in Low Gravity. NASA TM 88970, March 1987.

24. Sanchez Tariła, C.; Liñan, A.; Salva, J.A.; Corchero, G.; Juste, G.L.; and Esteban F.: Heterogeneous Combustion Processes under Microgravity Conditions, in Kaldeich, Brigitte, ed.: Combustion Experiments During KC-135 Parabolic Flights. ESA SP-1113, Aug. 1989, pp. 53-64.

25. Kimzey, J.H.: Skylab Experiment M479 Zero Gravity Flammability, in Skylab Results, Proc. Third Space Processing Symp. NASA Marshall Space Flight Center M-745, Vol. 1, NASA TM X-70752, June 1974, pp. 115-130.

26. Shipp, Martin; and Spearpoint, Michael: The Detection of Fires in Microgravity, in Kashiwagi, Takashi, ed.: Fire Safety Science. Proc. Fourth Inter. Symp. Inter. Assoc. for Fire Safety Sci., Boston, 1994, pp. 739-750.

27. Ramachandra, Prashant A.; Altenkirch, Robert A.; Bhattacharjee, Subrata; Tang, Lin; Sacksteder, Kurt; and Wolverton, M. Katherine: The Behavior of Flames Spreading over Thin Solids in Microgravity. Comb. and Flame, vol. 100,1995 , pp. 71-84.

28. Bryant, D.; and Judd, M.D.: The Effects of Gravity Level on Rate of Heat Release and Time to Ignition, in Experiment Results of ESA and CNES Parabolic Flight Campaigns - Tenth Anniversary of First ESA Parabolic Flight Campaign, Workshop Proc. ESA WPP-90, CNES ED/MV95-039, Feb. 1995, pp. 99-101.

29. West, Jeff; Tang, Lin; Altenkirch, Robert A.; Bhattacharjee, Subrata; Sacksteder, Kurt; and Delichatsios, Michael A.: Quiescent Flame Spread Over Thick Fuels in Microgravity. Twenty-Sixth Symp. (Inter.) on Comb., The Comb. Inst., Pittsburgh, 1996, pp. 1335-1343.

30. Steinberg, T.A.; and Stoltzfus, J.M.: Combustion Testing of Metallic Materials Aboard the NASA Johnson Space Center's KC135, in Royals, William T.; Chou, Ting C.; and Steinberg, Theodore A., eds.: Flammability and Sensitivity of Materials in Oxygen-Enriched Atmospheres: Eighth Volume. ASTM STP 1319, ASTM, West Conshohocken PA, 1997, pp. 170-188.

31. Kikuchi, Masao; Fujita, Osamu; Ito, Kenichi; Sato, Atsuki; and Sakuraya, Takashi: Experimental Study on Flame Spread over Wire Insulation in Microgravity. TwentySeventh Symp. (Inter.) on Comb., The Comb. Inst., Pittsburgh, 1998, in press.

32. Olson, Sandra L.; Ferkul, Paul V.: and T'ien James S.: Near-Limit Flame Spread Over a Thin Solid Fuel in Microgravity, Twenty-Second Symp. (Inter.) on Comb., The Comb. Inst., Pittsburgh, 1988, pp. 1213-1222.

33. Grayson, Gary; Sacksteder, Kurt R.; and T'ien, James S.: An Experimental Study of Low-Speed Concurrent-Flow Flame Spread over a Thin Fuel. The Comb. Inst., Central States Sec., Spring Tech. Meeting, Paper 3, April 1991.

34. McGrattan, K.B.; Kashiwagi, T.; Baum, H.R.; and Olson, S.L.: Effects of Ignition and Wind on the Transition of Flame Spread in a Microgravity Environment. Comb. and Flame, vol. 106, 1996, pp. 377-391.

35. Kashiwagi, T.; and Olson, S.L.: Radiative Ignition and Transition to Flame Spread Investigation (RITS|), in Curreri, P.A., McCauley, D., and Walker, C., eds.: Third U.S. Microgravity Payload One Year Report. NASA CP 1998-207891, Nov. 1998, pp. 97-117.

36. Egorov, S.D.; Belyaev, A.Yu.; Klimin, L.P.; Voiteshonok, V.S.; Ivanov, A.V.; Semenov, A.V.; Zaitsev, E.N.; Balashov, E.V.; and Andreeva, T.A.: Fire Safety Experiments on "Mir" Orbital Station, in Ross, Howard D., ed.: Third
International Microgravity Combustion Workshop. NASA CP 10174, Aug. 1995, pp. 195-199.

37. Greenberg, Paul S.; Sacksteder, Kurt R.; and Kashiwagi, Takashi: Wire Insulation Flammability Experiment: USML-1 1 Year Post Mission Summary, in Ramachandran, N.; Frazier, D.O.; Lehoczky, S.L.; and Baugher, C.R., eds.: Joint Launch + One Year Science Review of USML-1 and USMP-1 with the Microgravity Measurement Group. NASA CP 3272, vol. I, May 1994, pp. 631-655.

38. Walther, David C.; Fernandez-Pello, A. Carlos; and Urban, David L.: Smoldering Combustion Experiments in Microgravity, in Sacksteder, Kurt R., ed.: Fourth International Microgravity Combustion Workshop. NASA CP 10194, May 1997, pp. 369-374.

39. Olson, Sandra L.: The Effect of Microgravity on Flame Spread Over a Thin Fuel. NASA TM 100195, Dec. 1987.

40. Honda, L.K.; and Ronney, P.D.: Effect of Ambient Atmosphere on Flame Spread at Microgravity. Comb. Sci. and Technol., vol. 133, 1998, pp. 267-291.

41. Olson, S.L.; Stouffer, S.C.; and Grady, T.: Diluent Effects on Quiescent Microgravity Flame Spread Over a Thin Solid Fuel. The Comb. Inst., Eastern States Sec., Fall Tech. Meeting, Paper 70, Oct. 1989.

42. Olson, S.L.; Altenkirch, R.A.; Tang. L., Bhattarcharjee, S., and Hegde, U.: Diffusive and Radiative Transport in Fires Experiment: DARTFire, in Sacksteder, Kurt R., ed.: Fourth International Microgravity Combustion Workshop. NASA CP 10194, May 1997, pp. 393-398.

43. Ohlemiller, T.J.; and Villa, K.M.: Material Flammability Test Assessment for Space Station Freedom. NISTIR 4591, NASA CR 187115, June 1991.

44. Cordova, J.L.; Ceamanos, J.; Fernandez-Pello, A.C.; Long, R.T.; Torero, J.L.; and Quintiere, J.G.: Flow Effects on the Flammability Diagrams of Solid Fuels. in Sacksteder, Kurt R., ed.: Fourth International Microgravity Combustion Workshop. NASA CP 10194, May 1997, pp. 405-410.

45. Torero, J.; Bahr, N.; and Carman, E.: Assessment of Material Flammability for Micro-Gravity Environments. IAF-97-J.2.02, Oct. 1997.

46. Friedman, Robert: Fire Safety Practices and Needs in Human Crew Spacecraft. Jour. Appl. Fire Sci., vol. 2, 1992-1993, pp. 243-259.

47. Wieland, Paul $0 .:$ Designing for Human Presence in Space: An introduction to Environmental Control and Life Support Systems. NASA RP 1324, Jan. 1994.

48. Steisslinger, H.R.; Hoy, D.M.; McLin, J.A.; and Thomas, E.C.: Comparison Testing of the Space Shuttle Orbiter and Space Station Freedom Smoke Detectors. SAE Tech. Paper 932291, July 1993.

49. Thomas, Emory C.: Microgravity Fire Detection Problems-Fact or Fiction. SAE Tech. Paper 901215, July 1990.

50. Urban, David L.; Griffin, DeVon W.; Gard, Melissa Y.; and Hoy, Michael: Smoke Detection in Low-g Fires, in Sacksteder, Kurt R., ed.: Fourth International Microgravity Combustion Workshop. NASA CP 10194, May 1997, pp. 175-180.

51. Fuhs, Susan; Hu, Raymond; and McClure, George: Development of the Flame Detector for Space Station Freedom. SAE Tech. Paper 932106, July 1993.

52. Wieland, P.O.: Living Together in Space: The Design and Operation of the Life Support Systems on the International Space Station. Volume 1. NASATM-1998-206956/vol. 1, Jan. 1998.

53. McKinnie, James M.: Fire Response Aboard the International Space Station, SAE Tech. Paper 972334, July 1997.

54. Shipp, Martin; and Spearpoint, Michael: Fires in Microgravity. Fire Safety Eng., vol. 1, no. 4, Aug. 1994, pp. 41. 45 . 
55. Apostolakis, G.E.; Catton, I.; Issacci, F.; Jones, S.; Paul, M.; Paulos, T.; and Paxton, K.: Risk-Based Spacecraft Fire Safety Experiments. Reliability Eng. and Sys. Safety, vol. 49, 1995, pp. 275-291.

56. Urban, David L., Griffin, DeVon W.; and Gard, Melissa Y.: Detection of Smoke from Microgravity Fires. The Comb. Inst., Central States Sec., Tech. Meeting, Paper 1, April 1997.

57. Herber, Nikolaus; Müller, Roland; and Lucas, Jochen: Design and Development Status of the Columbus Orbital Facility Environmental Control and Life Support S/S and Equipment. SAE Tech. Paper 981663 , July 1998.

58. Jackson, M.A.; and Robins, I.: Gas Sensing for Fire Detection: Measurement of $\mathrm{CO}, \mathrm{CO}_{2}, \mathrm{H}_{2}, \mathrm{O}_{2}$, and Smoke Density in European Standard Tests. Fire Safety Jour., vol. 22, 1994, pp. 181-205.

59. Wilson, Steve; Limero, Thomas F.; Beck, Steve W.; and James, John T.: A Combustion Products Analyzer for Contingency Use During Thermodegradation Events on Spacecraft, in Krishen, Kumar, ed.: Sixth Annual Workshop on Space Operations, Applications, and Research, NASA CP 3187, vol. II, 1993, pp. 590-594.

60. Milke, James A.; and McAvoy, Thomas J.: Analysis of Signature Patterns for Discriminating Fire Detection with Multiple Sensors. Fire Technol., vol. 31, 1995, pp. 120-136.

61. Diamant, Bryce L.; and Humphries, W.R.: Past and Present Environmental Control and Life Support Systems on Manned Spacecraft. SAE Tech. Paper 901210, July 1990.

62. Friedman, Robert; and Dietrich, Daniel L.: Fire Suppression in Human-Crew Spacecraft. Jour. Appl. Fire Sci., vol. 1, 1991, pp. 243-258.
63. Williams, David E.: International Space Station Environmental Control and Life Support System Phase Two Design Overview. SAE Tech. Paper 961470, July 1996.

64. Tapscott, Robert: Halon Replacement Options for Use in Aircraft Fire Suppression Systems. DOT/FAA/AR-96/90, Sept. 1996.

65. Huttenbach, Robin C.; and Oram, Stephen D.: Life Support Thoughts on the Design of Safety Systems. SAE Tech. Paper 901248, July 1990.

66. Martin, Charles E.; and DaLee, Robert C.: Spacecraft Fire Detection and Suppression (FDS) Systems: An Overview and Recommendations for Future Flights. SAE Tech. Paper 932166, July 1993.

67. Smith, Richard L.; and Kashiwagi, Takashi: Expert Systems Applied to Spacecraft Fire Safety. Jour. Appl. Fire Sci., vol. 1, 1990-1991, pp. 103-113.

68. Rygh, Knut: Fire Safety Research in Microgravity: How to Detect Smoke and Flames You Cannot See. Fire Technol., vol. 31, 1995, pp. 175-185.

69. Goldmeer, Jeftrey S.; T'ien, James S.; and Urban, David L.: Combustion and Extinction of PMMA Cylinders during Depressurization in Low-Gravity. Fire Safety Jour., vol. 32, 1999, pp. 61-88.

70. King, Merrill K.; and Ross, Howard D.: Overview of the NASA Microgravity Combustion Program. AIAA Jour., vol. 36, 1998, pp. 1337-1343.

71. McKinnie, James M.: ISS US ECLSS Mission Control Operations. SAE Tech. Paper 981664, July 1998.

72. Ross, Rogard; Williams, Teresa A.J.; and Sargent, Donald: Post-Fire Cleanup on the Space Station. SAE Tech. Paper 941606, June 1994. 
Public reporting burden for this collection of information is estimated to average 1 hour per response, including the time for reviewing instructions. searching existing data sources, gathering and maintaining the data needed, and completing and reviewing the collection of intormation. Send comments regarding this burden estimate or any other aspect of this collection of information, including suggestions for reducing this burden, to Washington Headquarters Services. Directorate for Information Operations and Reports, 1215 Jefferson Davis Highway, Suite 1204, Arlington, VA 22202-4302, and to the Office of Management and Budget, Paperwork Reduction Project (0704-0188), Washington, DC 20503.

\begin{tabular}{|l|l|l|}
\hline 1. AGENCY USE ONLY (leave blank) & 2. REPORT DATE & 3. REPORT TYPE AND DATES COVERED
\end{tabular}

\section{TITLE AND SUBTITLE}

July 1999

Technical Memorandum

Fire Safety in the Low-Gravity Spacecraft Environment

6. AUTHOR(S)

Robert Friedman

7. PERFORMING ORGANIZATION NAME(S) AND ADDRESS(ES)

National Aeronautics and Space Administration

John H. Glenn Research Center at Lewis Field

Cleveland, Ohio 441.35-3191

WU-962-22-00-00

9. SPONSORING/MONITORING AGENCY NAME(S) AND ADDRESS(ES)

National Aeronautics and Space Administration

Washington, DC 20546-0001

8. PERFORMING ORGANIZATION REPORT NUMBER

$\mathrm{E}-11754$

10. SPONSORINGMONITORING AGENCY REPORT NUMBER

NASA TM-1999-209285

11. SUPPLEMENTARY NOTES

Prepared for the 29th International Conference on Environmental Systems cosponsored by SAE Aerospace. ASME. AIAA, Aerospace Medical Association, and AIChE, Denver, Colorado, July 12-15, 1999. Responsible person. Robert Friedman. organization code 6711 , (216) 433-5697.

12a. DISTRIBUTION/AVAILABILITY STATEMENT

12b. DISTRIBUTION CODE

Unclassified - Unlimited

Subject Category: 16

Distribution: Nonstandard

This publication is available from the NASA Center for AeroSpace Information. (301) 621-0390.

13. ABSTRACT (Maximum 200 words)

Research in microgravity (low-gravity) combustion promises innovations and improvements in fire prevention and response for human-crew spacecraft. Findings indicate that material flammability and fire spread in microgravity are significantly affected by atmospheric flow rate, oxygen concentration, and diluent composition. This information can lead to modifications and correlations to standard material-assessment tests for prediction of fire resistance in space. Research on smoke-particle changes in microgravity promises future improvements and increased sensitivity of smoke detectors in spacecraft. Research on fire suppression by extinguishing agents and venting can yield new information on effective control of the rare, but serious fire events in spacecraft.

\section{SUBJECT TERMS}

Aerospace safety; Fire detection; Fire extinguishers; Fire prevention; Flammability; Ignition; Microgravity application

\begin{tabular}{|c|c|}
\hline $\begin{array}{c}\text { 17. SECURITY CLASSIFICATION } \\
\text { OF REPORT }\end{array}$ & $\begin{array}{c}\text { 18. SECURITY CLASSIFICATION } \\
\text { OF THIS PAGE } \\
\text { Unclassified }\end{array}$ \\
Unclassified
\end{tabular}

19. SECURITY CLASSIFICATION
OF ABSTRACT
Unclassified



